\title{
Evaluation of seepage quantity of fill dam using 3D FEM analysis
}

\author{
Byoung-Il Choi i ${ }^{\text {i) }}$ Dong-Hoon Shin ${ }^{\text {ii)}}$, Ki-Young Kim ${ }^{\text {iii) }}$ and Chang-Kyu Kang ${ }^{\text {iv) }}$
}

\begin{abstract}
i) Researcher, Infrastructure Research Center of K-water Institute, 200beon-gil, Sintanjin-ro, Deajeon 307-711, Korea.
ii) Head Researcher, Infrastructure Research Center of K-water Institute, 200beon-gil, Sintanjin-ro, Deajeon 307-711, Korea.

iii) Senior Researcher, Infrastructure Research Center of K-water Institute, 200beon-gil, Sintanjin-ro, Deajeon 307-711, Korea.

iv ) Researcher, Infrastructure Research Center of K-water Institute, 200beon-gil, Sintanjin-ro, Deajeon 307-711, Korea.
\end{abstract}

\begin{abstract}
The resistance of a fill dam against seepage is a critical element in judging whether it is unstable or hazardous, and accordingly whether an excessive quantity of leaking water has occurred or whether soil particles are contained in the water leakage, etc. This is normally monitored after the installation of a measuring device that is used for the quantity of a water leakage in the downstream reaches of the dam body. In reality, however, the safety management aspect against water leakage is not easy because the current methods of measuring the quantity of water leakage are sometimes inaccurate as a result of being affected by rainfall or by the groundwater, etc. through the foundational ground or the surrounding mountainous area. Using two-dimensional (2D) numerical analysis that covers the largest section of the dam body, a process is generally performed when evaluating its stability against seepage. The quantity of seepage is first obtained by assuming that its bottom topography is in the simple form of a rectangle, it is then calculated by reflecting its sectional shape during this process of analyzing the seepage quantity. Considering that various forms of dams are being constructed on various types of ground, thanks to more recent technological advances, it is judged more appropriate to draw a conclusion by means of the results on reflecting the realistic shape and topographical conditions of the dam body through three-dimensional (3D) numerical analysis. Therefore, this study intends to present a method designed to carry out safety management by evaluating the correct quantity of water leakage that passes only through the dam body, having excluded other factors that include the amount of rainfall through the three-dimensional finite element method (3D FEM) analysis.
\end{abstract}

Keywords: 3D Analysis, Seepage Quantity, FEM Analysis

\section{INTRODUCTION}

The balance of a fill dam is evaluated in terms of its slope stability, its seepage stability or its seismic stability. The stability of a fill dam against seepage, in particular, is a critical element in judging whether or not it is safe, or whether an excessive quantity of water leakage has occurred, whether the soil particles are included in the water leakage, etc. This is normally monitored after the installation of a water leakage quantity measuring device in the downstream reaches of the dam body. In reality, however, in regards to safety management against water leakage it is not easy to evaluate because of the current methods of measuring the quantity of water leakage, it could be inaccurate as a result of being affected by rainfall or by the groundwater, etc. through the foundation ground or the surrounding mountain area.

By Using two-dimensional (2D) numerical analysis that covers the largest section of the dam body a process is generally performed when evaluating its stability against seepage. The quantity of seepage is first obtained by assuming that its bottom topography is in the simple form of a rectangle that is then calculated by reflecting its sectional shape while in the process of analyzing the seepage quantity. However, allowing for the fact that various forms of dams are being constructed on various types of ground thanks to a more recent advance in technology, it is judged to be more efficient to draw a conclusion by means of the results of more realism reflecting the shape and topographical conditions of the dam body through three-dimensional (3D) numerical analysis. This study intends to present a proper method to carry out safety management by evaluating the correct quantity of water leakage that passes only through the dam body. After excluding the other factors that include the amount of rainfall through the 3D FEM analysis. For numerical analysis, the seepage quantity due to the water level changes of the A dam was examined through PLAXIS 3D, a 
general-purpose geotechnical numerical analysis program, and the two-dimensional (SEEP/W) analysis was additionally performed, thereby comparatively analyzing the result values of the numerical analysis and the measured data.

\section{3D FEM NUMERICAL ANALYSIS CONDITIONS}

This study is aimed at a multi-purpose rock-fill dam that is located in Andong. The dam has a height of 73m, a length of $515 \mathrm{~m}$ and a total storage capacity of 595 million $\mathrm{m}^{3}$. The construction of the dam was started back in December 1984 and completed by December 31st, 1993. For the sake of FEM numerical analysis, this study had reflected the upper dam body and the shape of the bottom topography. It allowed for the lower ground of the dam body for analysis up to an elevation of 0 meters (EL. 0m). Figure 1 represents the sectional shape of the dam body made up of 5 different zones, and Table 1 shows the respective permeability coefficients for the zones that is required for the 3D seepage analysis. The mesh applied to the numerical analysis had been automatically generated by applying the Fine Mode to it and consisted of 29,173 elements and 42,656 nodes. Figure 2 shows the shape of strata and the shape of the mesh applied to the numerical analysis. In order to analyze the seepage quantities by water level, this study applied the following three water level stages: ${ }^{1)}$ the normal control water level of $163 \mathrm{~m}$, ${ }^{2)}$ the middle water level of $150 \mathrm{~m}$ and ${ }^{3)}$ the low water level of $137 \mathrm{~m}$ in the case of upstream water levels, and the $105 \mathrm{~m}$ bottom height of the dam body in the case of downstream water levels. Then performed a seepage analysis by the difference of the water head using the van Genuchten model. In addition to this, in the case of the permeability coefficient for the core that affected the seepage quantity most rapidly, the seepage analyses were performed by applying the design values and the quality test result values (Lab \& Field), with respect to the normal high water level on the basis of the A Dam Precise Safety Diagnosis Report (2012). Each analysis result value was compared with the $2 \mathrm{D}$ analysis result values. Table 2 shows the permeability coefficient applied to the core. As the target ranges for the numerical the numerical analysis, $482.6 \mathrm{~m}$ along the $\mathrm{X}$-axis, $730 \mathrm{~m}$ along the $\mathrm{Y}$-axis and $172 \mathrm{~m}$ along the Z-axis allowing for the height of the slopes around the dam were applied, and only the water flow along the $\mathrm{X}$-axis was admitted. The program used for numerical

(1) Core Zone

(2) Filter Zone

(3) Sand and Gravel Zone

(4) Rock Zone

(5) River Deposit

(5)-1 Random Zone el.133.0

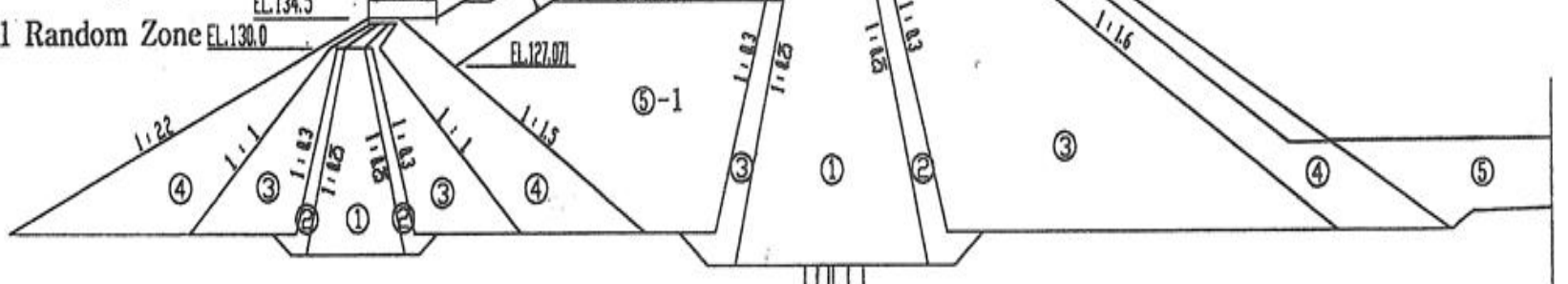

Fig.1. Sectional shape of the dam body.

Table 1. Physical properties applied.

\begin{tabular}{cccccccc}
\hline Material & Core & Filter & Sand and Gravel & Rock & Random & Bed Rock & Mountain Slope \\
\hline $\begin{array}{c}\text { Permeability } \\
(\mathrm{m} / \mathrm{s})\end{array}$ & $\begin{array}{c}1.0 \times 10^{-7} \\
\text { (Design Property) }\end{array}$ & $1.0 \times 10^{-5}$ & $1.0 \times 10^{-5}$ & $1.0 \times 10^{-5}$ & $1.0 \times 10^{-6}$ & $1.0 \times 10^{-9}$ & $1.0 \times 10^{-9}$ \\
\hline
\end{tabular}

Table 2. Seepage analysis condition.

\begin{tabular}{c|c|c|c}
\hline Classification & $\begin{array}{c}\text { Water Level } \\
\text { of Dam(m) }\end{array}$ & $\begin{array}{c}\text { Permeability } \\
\text { Coefficient(m/s) }\end{array}$ & Remarks \\
\hline At normal high water level & 163 & $1.0 \times 10^{-7}$ & Design value \\
\hline At normal high water level & 163 & $1.36 \times 10^{-8}$ & Quality control test result (Field) \\
\hline At normal high water level & 163 & $2.71 \times 10^{-8}$ & Quality control test result (Lab) \\
\hline
\end{tabular}


analysis was Plaxis 3D developed by Plaxis, a Dutch company, which is a FEM analysis program for exclusive use of geotechnical engineering that allows the 3D seepage analysis of dams.

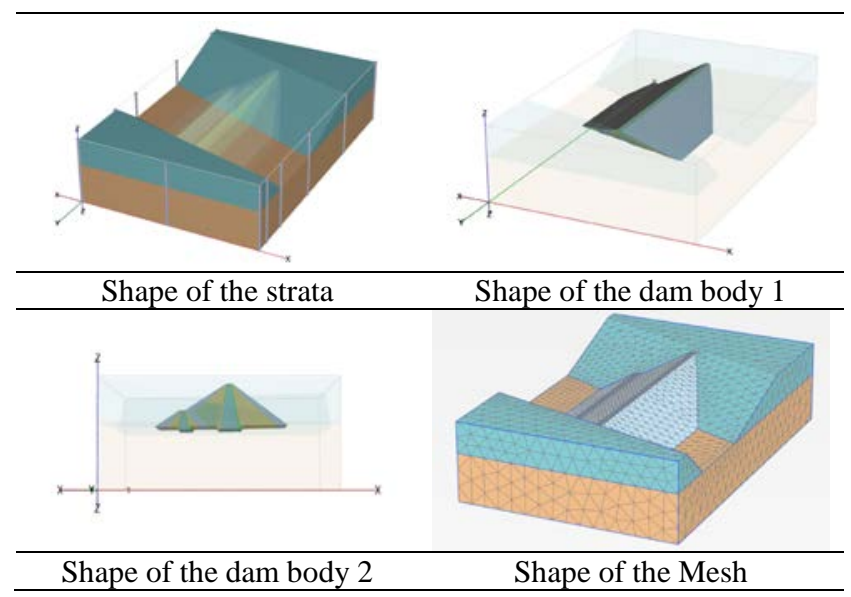

Figure 2. Shapes applied to numerical analysis.

\section{NUMERICAL ANALYSIS RESULTS}

In the case of the 3D seepage analysis, even though the seepage quantity is determined by various environmental factors such as the reservoir water level, the amount of rainfall, the inflow of water coming from the slopes around the dam body, etc., this study has grasped only the amount of water flowing into the dam body having carried out a 3D model that consists of the shape of the dam body. In the case of 2D seepage analysis, this study used GEO-SLOPE's SEEP/W, a finite element program and performed analysis of the steady states by the water head difference using the van Genuchten model at the water levels of three points (163m, 150m, 137m) just as in the same circumstance as of 3D numerical analysis. The same permeability coefficient for the core was applied to both the 2D and 3D analysis. In the case of the 2D analysis, this study had multiplied it by the length of $515 \mathrm{~m}$ along the dam axis this was in order to obtain the seepage quantity. Then presented $70 \%$ of the seepage quantity (the A Dam Precise Diagnosis Report, 2012) that reflected the shape of the dam body as its result. Most of the 2D numerical analysis results that reflected only $70 \%$ by taking the shape of the bottom topography of the dam body into consideration were found to be higher than the 3D analysis results that allowed for $100 \%$ of its bottom topography. The results are the same as shown in Table 3, Figure 3 shows the analysis results by the water level.

Table 3. Seepage quantities at normal high water level.

\begin{tabular}{ccccc}
\multirow{2}{*}{ Permeability } & \multicolumn{4}{c}{ Seepage Quantity [L/min] } \\
\cline { 2 - 5 } & & $\mathbf{1 6 3 m}$ & $\mathbf{1 5 0 m}$ & $\mathbf{1 3 7 m}$ \\
\hline $\mathrm{K}=1 * 10^{-7} \mathrm{~m} / \mathrm{s}$ & $3 \mathrm{D}$ & 133.26 & 65.43 & 28.25 \\
\cline { 2 - 5 } & 2D & 182.28 & 123.27 & 44.03 \\
\hline $\mathrm{K}=1.36^{*} 10^{-8} \mathrm{~m} / \mathrm{s}$ & 3D & 32.25 & 18.69 & 9.94 \\
\cline { 2 - 5 } & $2 \mathrm{D}$ & 26.25 & 24.61 & 10.21 \\
\hline $\mathrm{K}=2.7 * 10^{-8} \mathrm{~m} / \mathrm{s}$ & 3D & 49 & 26.5 & 13.42 \\
\cline { 2 - 5 } & $2 \mathrm{D}$ & 51.94 & 36.69 & 16.04
\end{tabular}

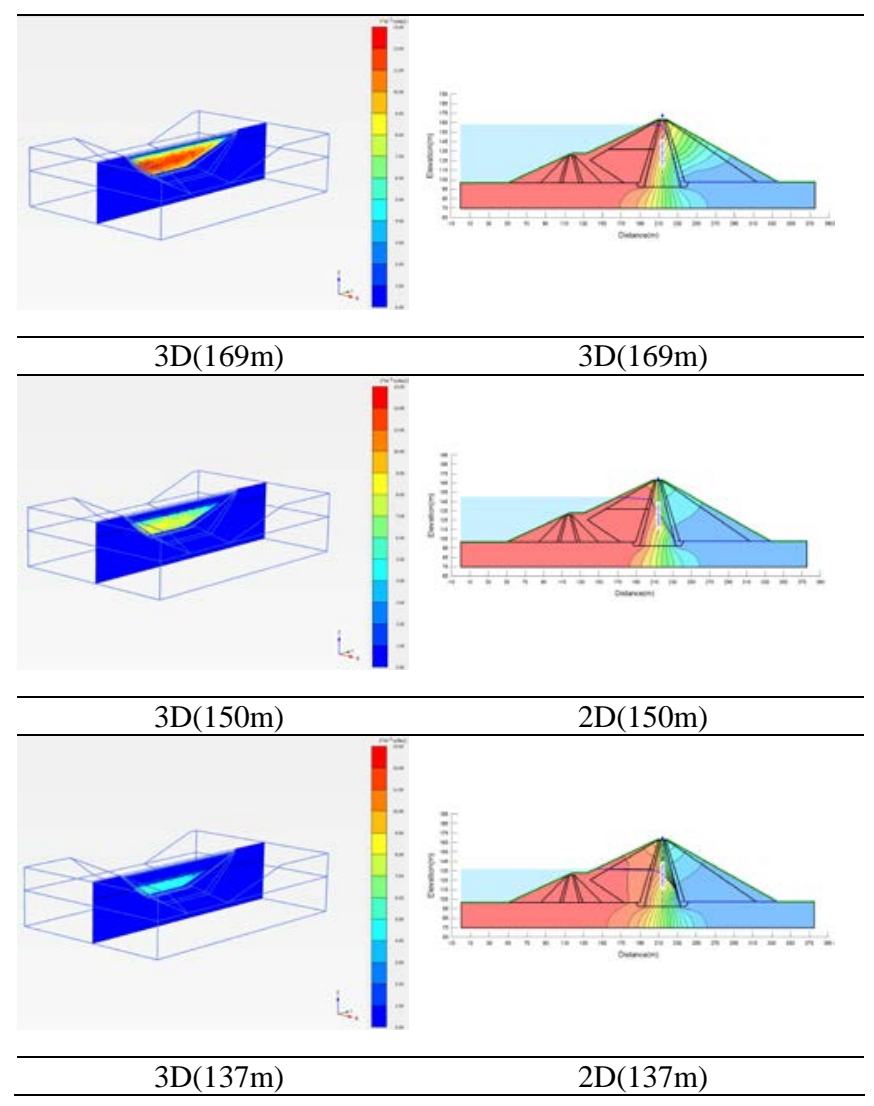

Figure 3. Seepage analysis results by water level.

\section{ANALYSIS OF MEASURED VALUES}

In order to correctly analyze the numerical analysis results, the data measured at the A Dam and the actual amount of rainfall over the past three years from November 2011 through to October 2014 were marked by date, and the results were then obtained as shown in Figure 4 . Figure 4 states that the actual seepage 
quantity was found to be heavily affected not only by the water level of the dam body but also by the rainfall.

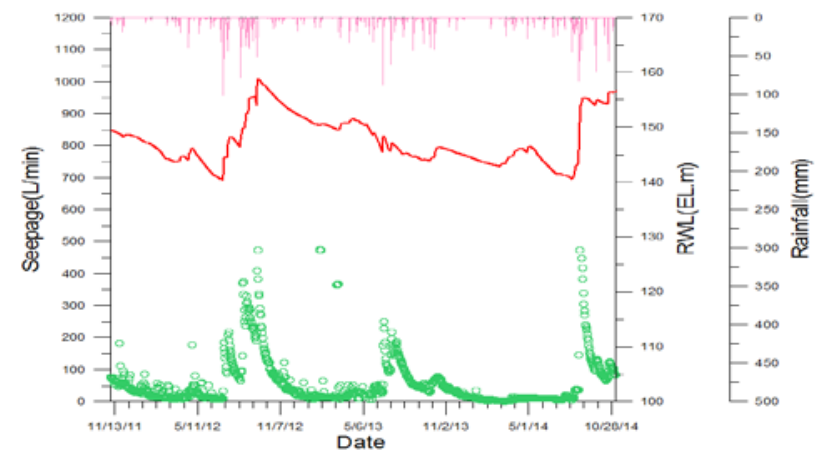

Figure 4. A time-series graph of the measured seepage quantities of the A Dam.

This study has analyzed the seepage quantity measurement results by a low water level except the unusual measured values indicating the occurrence of a design leakage quantity of over $290 \mathrm{~L} / \mathrm{min}$. Figure 5 shows the respective seepage quantities according to different water levels over the past three years, and the 2D and 3D analysis results obtained by applying the design permeability coefficients that represented the result values closest to the measured values are shown together in the form of a line graph. As mentioned earlier, in regards to factors governing the seepage quantity, it could be seen that the reason for huge differences between the numerical analysis result values and the measured values was again due to the fact that the seepage quantity was affected not only by the water level of the reservoir but also by the rainfall, and the groundwater, etc.. In order to perform a comparison with the seepage quantity numerical analysis result values with exception to the water level conditions by which the seepage quantity is found to be most affected by the water level of the reservoir, only the measured values for the four months from November through to February corresponding to a dry period were classified by water level and compared with the numerical analysis result values, as shown in Figure 6. As a result, most measured values are found to be included in the solid line that represents the 2D numerical analysis results, the rainfall amounts are also included in the data for all fourth months. Moreover, allowing for the fact that other contributing factors such as the influence of the groundwater, etc. are also included, it could be seen that the 3D analysis result values had presented figures that are significantly close to the measured values.

\section{CONCLUSION}

In order to evaluate the correct seepage quantity for each low water level for the A Dam, seepage analyses

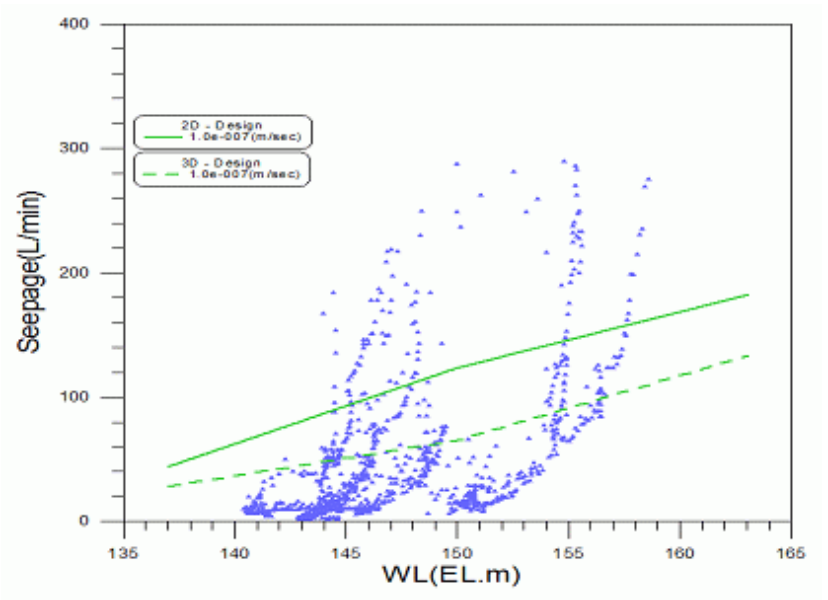

Figure 5. Seepage analysis results by water level.

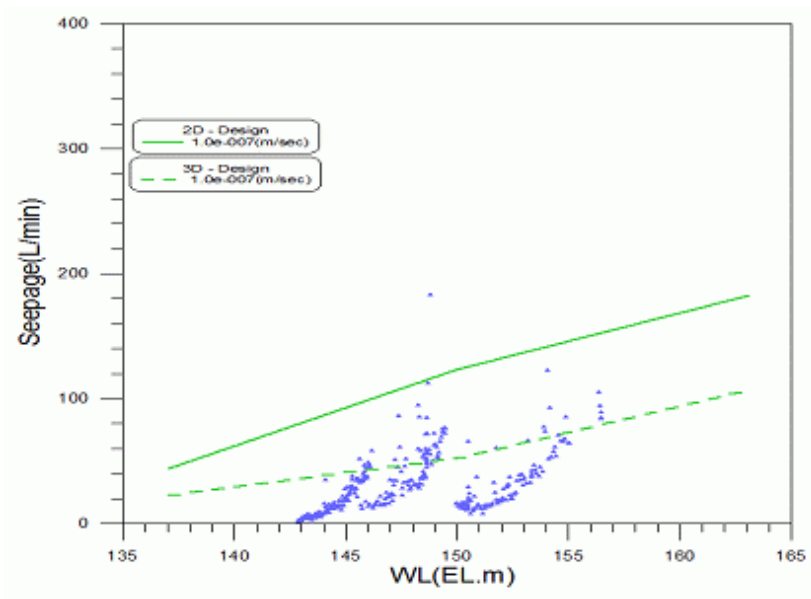

Figure 6. Seepage analysis results by water level (November December).

were performed on the dam body, its topographical conditions, the slopes around the dam, etc. using PLAXIS 3D that is capable of reflecting them on a three-dimensional basis. The seepage analyses were also performed under the same conditions using SEEP/W, a 2D program and the 2D analysis result values that were then compared with the $3 \mathrm{D}$ analysis result values. By comparing the $2 \mathrm{D}$ and $3 \mathrm{D}$ analysis result values with the actual measured values for the $\mathrm{A}$ Dam, we have obtained the following conclusions:

1) Numerical analyses were performed by applying the van Genuchten model through the use of different permeability coefficients for the core and under various low water level conditions. According to the results of the analysis, most of the 2D numerical analysis result values were found to be higher than the 3D numerical analysis result values. These differences may be explained by the fact that even though the same analysis model was applied to both the 2D and 3D analyses, their result values are completely different due to the mutually different characteristics of the two programs. 
2) In order to compare the numerical analysis results with the measured values, this study had analyzed the seepage quantity measurement results by low water level except for the unusual measured values indicating the occurrence of a designed leakage quantity of over $290 \mathrm{~L} / \mathrm{min}$. Overall, the measured values and the numerical analysis values were found to be very different from each other, and this concept is due to the fact that the seepage quantity is affected not only by the water level of the reservoir but also by various activities of nature such as rainfall, the groundwater, etc.

3) Data for specific measured values over the four months from November through to February while corresponding to a dry period were classified by water level and was compared with the numerical analysis result values. As a result of this, it could be seen that the $3 \mathrm{D}$ analysis result values represented figures that were significantly close to the measured values. Although it is difficult to evaluate the actual leakage quantity for the A Dam by using only low water levels and the amount of rainfall as variables, it is judged necessary to suspect the possibility of something abnormal existing in the dam body. That is if seepage quantities higher than the $3 \mathrm{D}$ analysis values continue to be measured at least in a season corresponding to a dry period on the basis of the numerical analysis results.

\section{ACKNOWLEDGEMENTS}

This research was supported by a grant (14SCIP -B065985-02) from Smart Civil Infrastructure Research Program funded by Ministry of Land, Infrastructure and Transport(MOLIT) of Korea government and Korea Agency for Infrastructure Technology Advancement (KAIA).

\section{REFERENCES}

1) Zardari, M. .A., Mattsson, H., and Knutsson, S.(2012): 3D finite element analyses of a corner at Aitik tailings Dam in Sweden, Proceedings of the 13th International Symposium on Environmental Issues and Waste Management in Energy and Mineral Production (SWEMP), 444-453

2) Chen Qun and Zhang, L, M.(2006): Three-dimensional analysis of water infiltration into the Gouhou rockfill dam using saturated-unsaturated seepage theory, Canadian Geotechnical Journal, Vol. 43, No. 5, 449-461

3) Malkawi, A.I.H., Al-Sheriadeh, M.(2000):Evaluation and Rehabilitation of Dam Seepage Problems, A Case Study: Kaferin Dam, Eng. Geol. Vol.56, 335-345 